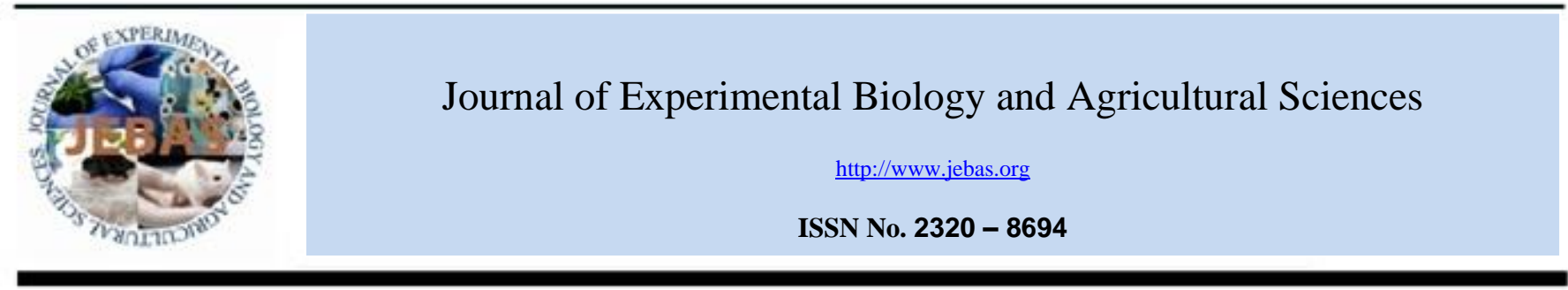

\title{
PHYTOCHEMICAL ANALYSIS, ANTIMICROBIAL SCREENING AND HYPOGLYCEMIC EFFECT OF SOME SELECTED MEDICINAL PLANT EXTRACT FROM OMAN
}

\section{S Hemadri Reddy*, Aisha Khalid AL-Hinai, Hajer Hafed AL-Yaqoobi and Fatima Jafar AL-Ajmi}

Department of Applied Science, Higher College of Technology, Al Khuwair, Po box: 74, postal code: 117, Muscat, Sultanate of Oman

Received - December 30, 2015; Revision - January 15, 2016; Accepted - May 03, 2016

Available Online - May 03, 2016

DOI: http://dx.doi.org/10.18006/2016.4(2).218.224

\section{KEYWORDS}

Medicinal plants

Phytochemical screening

Plant extraction

Antimicrobial study

in-vivo assay in mice

Blood sugar level

Body mass

\begin{abstract}
In present study phytochemical screening and antimicrobial potential of three Omani traditional medicinal plants i.e. Ajuga iva, Pteropyrum scoparium and Rhazya stricta was carried out. The information generated from study will be helpful in drug administration and developing commercial drug form these studied traditional plants. All three selected plants were air dried under natural condition and phytochemical screenings were carried out under laboratory conditions. Antimicrobial properties of the selected plants were carried out against the selected microorganisms i.e. Bacteria (E.coli, Staphylococcus and Bacillus species) and fungi (Trichoderma and Aspergillus). Further, selected plants were also used to test their effect on reducing diabetic incidence. Results of study revealed that selected plants have significant inhibitory effect on the multiplication of selected microorganisms. Similarly oral administration of plant extract also reduced the blood sugar level of the treated mice; it started reducing after 1 week of treatment and continued till 21 days of exposure as compared to control. Further, phytochemical screening of these plants indicated that these plants contain many of chemical substances which had important role in the reducing blood sugar level.
\end{abstract}

* Corresponding author

E-mail: hemadrisvu2020@gmail.com (S Hemadri Reddy)

Peer review under responsibility of Journal of Experimental Biology and Agricultural Sciences.

Production and Hosting by Horizon Publisher India [HPI] (http://www.horizonpublisherindia.in/).

All rights reserved.
All the article published by Journal of Experimental Biology and Agricultural Sciences is licensed under a Creative Commons Attribution-NonCommercial 4.0 International License Based on a work at www.jebas.org.

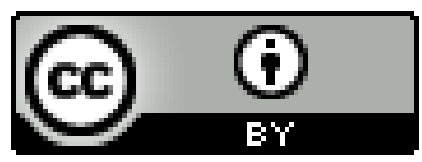




\section{Introduction}

Plants are important source of traditional medicine and are useful in the treatment of various diseases with fewer side effects (Bako et al., 2005). Traditional medical practices are not only useful in disease healing but also have significant contribution in the discovery of pharmaceutically active substances from plants (Principe, 1991; Pearce \& Puroshothaman, 1992) which can contribute in the commercial production of drugs. The role of plant biodiversity in health care has been well documented from ancient time (Posey, 1999). Literature survey suggested that worldwide more than 50,000 plant species are successfully used for medicinal purposes and among these almost $13 \%$ are flowering plants (Schippmann et al., 2002). Various active ingredients like alkaloid, glycoside, saponin, essential oil, tannins and mucilages have been isolated from various plant parts such as root, stem, leaves, bark, fruit and seeds; these phytochemicals determine a definite curing physiological response in the treatment of various humans and other animal ailments (Adhikari et al., 2010). Because of the accelerated local, national and international interest in recent years, the demand for medicinal and aromatic plants has increased manifold and in pharmaceutical industry views plant wealth are a source of income. Due to easy availability, less side-effects and sometimes only source of health care, the demand for medicinal plants is increasing in both developing and developed countries.

Ajuga iva is a small $(5-10 \mathrm{~cm})$ wooly, aromatic perennial herb with well documented anti-ulcerous, hypoglycemic and antiinflammatory activities. The anti-ulcerous activity of Ajuga iva was confirmed experimentally. Similarly, medicinal properties of $P$. scoparium and $R$. stricta were also reported by various researchers (Emad El-deen, 2005). The Hypoglycemic effect of the lyophilized aqueous extract of these plants was also shown in normal and streptozotocin diabetic rats. Due to various medicinal values, present study was aimed to explore the antimicrobial and anti hypoglycemic properties of these selected Omani plants. Furthermore, phytochemical analysis was also carried out for justifying the possible reason of antimicrobial and anti hypoglycemic efficacy.

\section{Materials and methods}

\subsection{Plant materials and extraction}

The plant materials Ajuga iva, P. scoparium and R. stricta were collected from Rustaq during February 2014. Different plant parts like leaves, stem and root were air dried under natural conditions for two days and dried plant materials were powdered by using home blender and $40 \mathrm{~g}$ of plant extract were extracted with $200 \mathrm{ml}$ of ethanol for 6 hours at room temperature at orbital shaker through maceration method of extraction. The extracts were filtered through whatman No.1 filter paper and residues were also extracted twice by using $400 \mathrm{ml}$ of ethanol. The final extract is subjected for Rota evaporation at $90^{\circ} \mathrm{C}$ under constant pressure with respect to time duration. Different concentrations ranging from $0.1,0.5 \%$ and $1.0 \%$ were made from extracted crude extracts with DMSO and distilled water. The concentrated crude extracts obtained through Rota evaporator were weighed and dissolved in DMSO initially and then final volume was made up to the required concentrations $(1 \mathrm{~g} / 100 \mathrm{ml}, \mathrm{w} / \mathrm{v})$.

\subsection{Phytochemical screening}

Phytochemical screening was carried out according to Reddy et al. (2012). Different crude extracts collected from Rota evaporator were qualitatively tested for the presence of various phytochemical constituents by using standard methods given by Brain \& Turner (1975) and the extractive values were calculated by suggested protocols.

\subsection{Screening of Antimicrobial Activity}

In-vitro antimicrobial screening were carried out under laboratory conditions, for this various microorganism were collected from microbiology laboratory, HCT, Muscat with stain numbers of E.coli (ATCC 25922), $S$ aureus (ATCC 25932), B Subtilis (ATCC 6633), T. harzianum (ATCC 20847) and A. brasiliensis (ATCC 16404). All the suggested microorganisms were cultured on recommended cultural medium and finally transfer \& maintained on agar broth for $\mathrm{O} / \mathrm{N}$.

Antimicrobial activity of various plants extracts viz. A. iva, $P$. scoparium and $R$. stricta have been carried out by using disc diffusion method (Kavanagh, 1972). The inhibitory effect of each extracts was compared with the standard antibiotics penicillin and mycostatin against bacteria and fungi respectively.

\subsection{Effect of various extracts on blood sugar and body weight}

Three concentrations viz $0.1 \%, 0.5 \%$, and $1 \%$ of individual extracts were prepared by dissolving one gram of each crude extract in $5 \mathrm{ml}$ DMSO (Dimethylsulfoxide) to obtain 1\% stock solution from which experimental concentrations namely $0.1 \%, 0.5 \%$ and $1.0 \%$ were prepared in sterile distilled water at pH 9 (Ali et al., 2000). Thirty locally bred white male mice with initial weighing of 15 - $30 \mathrm{~g}$ were obtained from Animal house, Higher College of Technology (HCT), Al-Khuwair, Sultanate of Oman for testing effect of various extracts on blood glucose level. All the mice were divided into 10 groups; each group had 3 mice and these were acclimatized 4 days prior to experimentation at a temperature of $25^{\circ} \mathrm{C}$. Before applying various treatments blood glucose level was measured with the help of Glucometer. 
Table 1 Phytochemical screening of different plant extract.

\begin{tabular}{|c|c|c|c|c|}
\hline \multicolumn{2}{|l|}{ Test } & A.iva & P. scoparium & R.stricta \\
\hline \multicolumn{2}{|c|}{ Alkaloids (wagner`s test) } & +++ & +++ & +++ \\
\hline \multicolumn{2}{|c|}{ Carboxylic acid } & - & - & - \\
\hline \multicolumn{2}{|c|}{ Coumarins } & +++ & +++ & +++ \\
\hline \multirow[t]{2}{*}{ Fixed oil } & Test 1 & +++ & +++ & - \\
\hline & Test 2 & +++ & +++ & - \\
\hline \multirow[t]{3}{*}{ Flavonoids } & Ferric chloride test & +++ & +++ & +++ \\
\hline & Shimoda`s test & +++ & +++ & +++ \\
\hline & Zinc-HCl & +++ & +++ & +++ \\
\hline \multicolumn{2}{|l|}{ Phenols } & +++ & +++ & +++ \\
\hline \multicolumn{2}{|l|}{ Quinones } & - & - & - \\
\hline \multicolumn{2}{|l|}{ Resins } & +++ & +++ & ++ \\
\hline \multicolumn{2}{|l|}{ Saponins } & - & +++ & +++ \\
\hline \multicolumn{2}{|c|}{ Steroids (Salkowski test) } & +++ & +++ & +++ \\
\hline \multicolumn{2}{|c|}{ Tanmins (Ferric chloride test) } & +++ & +++ & +++ \\
\hline \multicolumn{2}{|c|}{ Glycosides (Borntragers test) } & +++ & +++ & + \\
\hline
\end{tabular}

Here +++ represents the highest amount; ++ represents the moderate level presence; + represents the availability of less amount; represents the absence of particular ingredients; all the values presented in the above table are the mean of three replicates.

They were fed pellets regularly with the same amount to each cage, given tap water. Group 1 (control), was fed by simple tap water and labelled as control while the Group 2, 3, 4 were treated with $0.1 \%, 0.5 \%$ and $1 \%$ of $A$. iva extract, Group 5, 6, 7 , were treated with $0.1 \%, 0.5 \%$ and $1 \%$ of $P$. scoparium extract and Group 8, 9, 10 were treated with $0.1 \%, 0.5 \%$ and $1 \%$ of $R$. stricta extract respectively by oral gavage. $1 \mathrm{ml}$ of each extract was given regularly by syringe for duration of 21 days. After 21 days, all the mice were weighed and blood glucose level was measured by Glucometer (one touch select AW06505403A).

\section{Results and Discussion}

3.1 Phytochemical screening of selected plant materials

Results of the phytochemical screening of $A$. iva and $P$. scoparium revealed the presence of various phyto-chemicals like alkaloids, coumarins, oils, flavonoids, phenols, resins, steroids, tannins and glycosides. Furthermore, present study also suggested that presence of carboxylic acids and quinines are limited and not reported from all the tested plant extracts. Table 1 revealed the presence of saponins in $P$. scoparium extract while it was not reported in the A. iva extract. Also the presence of alkaloids, coumarins, flavonoids, phenols, resins, saponins, steroids, and tannins was reported from the $R$. stricta while the presence of quinones, oils, carboxylic and glycosides was not reported from the same. According to Wadood et al. (2013) medicinal plants possessing various bioactive secondary metabolites which are responsible for various antimicrobial properties like antifungal, antibacterial and antiinflammation. Therefore the results obtained from present study indicated the presence of various bioactive substances which are responsible for various antimicrobial properties of these extracts. Occurrence of phytochemicals such as terpenoids, alkaloids, phenolics, flavonoids, saponins and cardiac glycosides are also responsible for exhibiting hypoglycaemic potential. Medicinal plant products yield good results in the management of various forms of hyperglycaemia as compared to synthetic drugs that usually contain single active principle, that on continuous administration could predispose various forms of idiosyncrasies in diabetic patients (Ahmad et al., 1983; Anila et al., 2002; Jung et al., 2006; Sanni, 2007).

3.2 Effect of various extracts on body weight and blood sugar levels

\subsubsection{Body weight}

Result of study suggested that diversity of weight loss or gain is depending on the concentration and type of extract. Among the various tested extracts, $A$. iva reported least effective in body weight gain while $P$. scoparium and $R$. stricta are at par to each other and showed superiority over A. iva. Various concentration of $P$. scoparium and $R$. stricta are significantly differ than the A. iva but these two are not significantly differ than the control. Mice treated with three different concentration of $A$. iva viz $0.1 \%, 0.5 \%$ and $1.0 \%$ shows $0.92 \mathrm{~g}$ , $0.25 \mathrm{~g}$ and $0.1 \mathrm{~g}$ weight gain respectively while this weight gain was $4.05 \mathrm{~g}$ in control (Table 2), here it was also reported that increasing concentration of extract have negative impact on the weight gain and least weight gain was reported in the mice treated with heighted concentration $(1.0 \%)$ of A.iva.

Further, it was reported that mice treated with selected concentration $(0.1 \%, 0.5 \%$ and $1.0 \%)$ of $P$. scoparium shows $1.25 \mathrm{~g}, 1.3 \mathrm{~g}$ and $1.15 \mathrm{~g}$ respectively, no significant difference was reported between various concentration and all the treatments are almost at par to each other. Positive impact of 
$R$. stricta treatment was observed on the treated mice and with the increasing extract concentration rate of weight gain was also increased from $0.48 \mathrm{~g}$ to $1.85 \mathrm{~g}$ respectively. The suppression of weight gain is a dose dependent and it may be because of the presence of an orexigenic compounds in the extracts (Reddy et al., 2015).

\subsubsection{Hypoglycemic study}

Blood sugar level of the experimental mice was analyzed after 21 days of treatment application and reported that tested plant extract have hypoglycemic effect. Among various tested extracts, $R$. stricta extract was found most suitable in reducing blood sugar level and all the tested concentration of this extract effectively reduced the blood glucose level. This extract was followed by the A.iva extract and it also showed hypoglycemic effect. P. scoparium reported as least effective treatment and did not show any effect on reducing blood glucose level. Further, it was noticed that all the concentration of A.iva extract $(0.1,0.5 \& 1.0 \%)$ did not show any significant differences and all were showing at par result $(0.01,0.02 \&$ $0.05 \mathrm{mmol}$ ). Whereas mice treated by all the concentrations of $R$. stricta showed reduction in blood sugar level and the effect was more profound with the increasing the doses of extract and it was reported at $0.1 \%(0.12 \mathrm{mmol}), 0.5 \%(0.27 \mathrm{mmol})$ and at $1 \%(0.37 \mathrm{mmol})$. While the mice treated with the different concentration of $P$. scoparium extract did not reduced blood glucose level. Results of the study revealed that the extract of R. stricta and A. iva are more pronounced in reducing blood glucose level than $P$. scoparium. The hypoglycemic effect produced by $R$. stricta extracts may be due to its positive effect on the insulin releasing mechanism; this is showing resembling with the mechanism of sulfonylureas (Miura et al., 2001; Okine et al., 2005). Findings of this study suggested that the $R$. stricta extract have remarkable effect on the decreasing serum glucose level. This research supports the inclusion of this plants in formulation of traditional antidiabetic, and the formulations made using the identified effective extract and fraction of this plant could serve the purpose better than the existing formulations with crude aqueous extract since the experimental plants used in this study are used all over the Sultanate of Oman as blood sugar control plant material traditionally.

\subsection{Antimicrobial activity}

Antimicrobial activity of ethanolic extracts of selected plant extracts was reported by disc diffusion method against the selected microorganisms while recommended antibiotic and fungicide disc was used as control treatment. Results of the study revealed that all three plant extracts have antimicrobial properties against the selected bacteria and fungi. Among the three plant extracts, $R$. stricta extract showed highest zone of inhibition against all tested microorganisms and it shows superiority over the other two extracts of $A$. iva and $P$. scoparium (Table 3, Figure 1). The antimicrobial property of glycosides ensures its use as an anti-infective agent (Rucker et al., 1992; Murakami et al., 1993). Coumarins which was reported in all the plant extracts, are well known for its antitumor, antibacterial and anthelmintic properties (Chhabra et al., 1984). Highest zone of inhibition (21.6 mm) was reported in the well exposed by $1 \%$ R. stricta and it was also against the Staphylococcus. Further, it was reported that zone of inhibition is directly proportional to the concentration and highest zone of inhibition was reported from the disc containing highest concentration of extract. The higher activity of ethanolic plant extracts against E. coli, S.aureus and $B$. subtilis indicates the presence of antimicrobial agents in the tested plants which are useful in curing various skin infections, as these organisms often cause various skin infections in human beings (Reddy et al., 2012). While antifungal assay also suggested the antifungal properties of these plant extracts and it caused reasonable zone of inhibition against the tested fungal cultures (Table 3, Figure 1).

Table 2 Effect of ethanolic plant extracts on body weight and blood sugar.

\begin{tabular}{|c|c|c|c|c|c|c|c|}
\hline \multirow{2}{*}{$\begin{array}{l}\text { Name of plant } \\
\text { material }\end{array}$} & \multirow{2}{*}{$\begin{array}{l}\text { Concentration of } \\
\text { plant extracts }\end{array}$} & \multicolumn{2}{|c|}{ Body Weight in Grams } & \multicolumn{4}{|c|}{ Blood sugar level m mol } \\
\hline & & Before & After 21 days & $\begin{array}{c}\text { Mean } \\
\text { difference }\end{array}$ & Before & After 21 days & $\begin{array}{c}\text { Mean } \\
\text { difference }\end{array}$ \\
\hline Control & & $22.1 \pm 2.00$ & $26.15 \pm 1.38$ & $4.05 \uparrow$ & $6.32 \pm 2.95$ & $7.7 \pm 0.51$ & $1.38 \uparrow$ \\
\hline \multirow{3}{*}{ A. iva } & $0.1 \%$ & $23.45 \pm 2.75$ & $24.37 \pm 1.68$ & $0.92 \uparrow$ & $5.85 \pm 0.91$ & $5.84 \pm 1.52$ & $0.01 \downarrow$ \\
\hline & $0.5 \%$ & $25.77 \pm 1.33$ & $26.02 \pm 1.66$ & $0.25 \uparrow$ & $6.07 \pm 0.17$ & $6.05 \pm 0.21$ & $0.02 \downarrow$ \\
\hline & $1.0 \%$ & $19.4 \pm 0.85$ & $19.5 \pm 1.55$ & $0.1 \uparrow$ & $4.85 \pm 0.26$ & $4.80 \pm 0.35$ & $0.05 \downarrow$ \\
\hline \multirow{3}{*}{ P. scoparium } & $0.1 \%$ & $25.82 \pm 0.86$ & $24.57 \pm 2.12$ & $1.25 \downarrow$ & $4.7 \pm 0.63$ & $4.82 \pm 0.52$ & $0.12 \uparrow$ \\
\hline & $0.5 \%$ & $26.2 \pm 1.04$ & $24.9 \pm 1.27$ & $1.3 \downarrow$ & $5.85 \pm 0.49$ & $6.12 \pm 0.33$ & $0.27 \uparrow$ \\
\hline & $1.0 \%$ & $24.35 \pm 1.04$ & $23.2 \pm 1.30$ & $1.15 \downarrow$ & $3.95 \pm 0.81$ & $4.32 \pm 0.19$ & $0.37 \uparrow$ \\
\hline \multirow{3}{*}{ R. stricta } & $0.1 \%$ & $22.3 \pm 1.95$ & $22.82 \pm 1.82$ & $0.48 \downarrow$ & $5.3 \pm 0.61$ & $4.8 \pm 0.13$ & $0.50 \downarrow$ \\
\hline & $0.5 \%$ & $24.65 \pm 1.93$ & $25.55 \pm 2.33$ & $0.9 \downarrow$ & $6.3 \pm 0.63$ & $4.9 \pm 0.0535$ & $\overline{1.40 \downarrow}$ \\
\hline & $1.0 \%$ & $25.02 \pm 3.19$ & $23.17 \pm 3.48$ & $1.85 \downarrow$ & $7.6 \pm 1.57$ & $5.25 \pm 0.09$ & $2.35 \downarrow$ \\
\hline
\end{tabular}

Here all the values expressed are the SEM \pm of 3 replicates calculated with descriptive statistics maintained for 21 days with plant extracts treatment. 


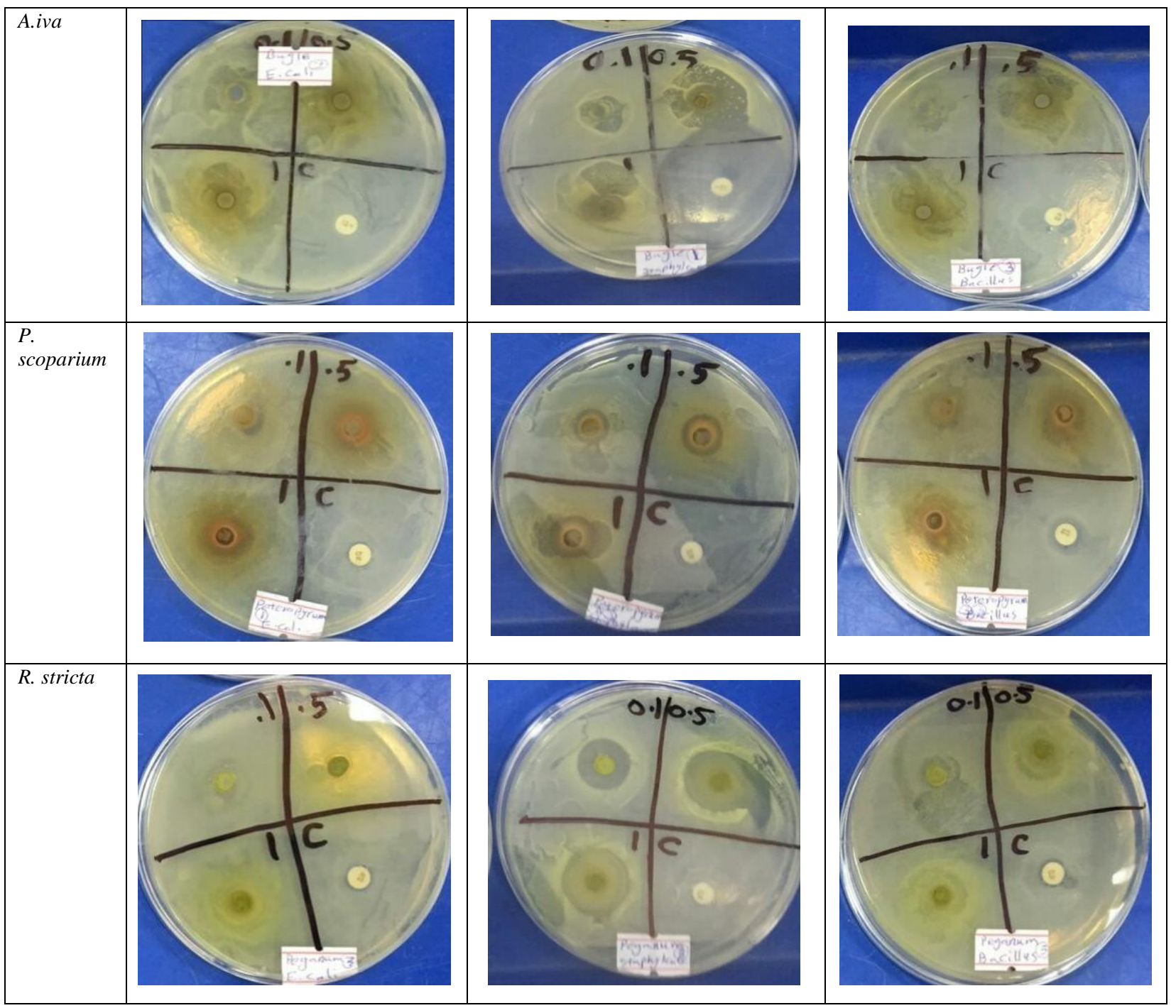

Figure 1 Antibacterial activity of three different plant extracts against E.coli, Staphylococcus and Bacillus (C: control; 1:0.1\%, 2:0.5\%,3: $1.0 \%)$

Among various texted plant extracts, highest zone of inhibition was noticed with $R$. stricta extract against $T$. harzzianum (10.6 $\mathrm{mm})$ while the least antifungal activity was noticed in the $A$. iva extracts which was against the A. brasiliensis (5mm).

\section{Conclusion}

Results of this study experimentally established the medicinal as well antimicrobial properties of the selected medicinal plants. A significant effect of these plants was reported on the reducing blood sugar and in maintaining body weight, since these plant materials are used by Omanis around the Sultanate of Oman as traditional medicine against diabetes, reducing weight and to control many more microbial diseases. The preliminary phytochemical screening indicates that ethanolic plant extracts consist different types of phytoconstituents such as alkaloids, coumarins flavonoids, phenols, quinones etc., possess significant bioactive properties. The study of antimicrobial efficacy against both bacteria and fungi revealed that these three plants have ability to kill or inhibit the growth of bacteria and fungi which experimentally support the use of these plants in traditional medicine by traditional healers. The Hypoglycemic role of all the three plant extracts revealed a great avenue for exploiting the herbal medicines to control one of the world's most popular health concerns. The further researches on the same plants are highly recommended to trace bioactive principles with specific functional groups involved to trace their medicinal importance. Therefore the present investigation helps to trace herbal medicine useful to treat diabetes and also these traditional plants can be used as antimicrobials. 
Table 3 Antimicrobial activity of three extracts against selected microorganisms.

\begin{tabular}{|c|c|c|c|c|c|c|}
\hline \multirow[t]{3}{*}{ Treatment } & \multirow{3}{*}{$\begin{array}{c}\text { Concentration of plant } \\
\text { extracts }\end{array}$} & \multicolumn{5}{|c|}{ Zone of Inhibition (mm) } \\
\hline & & \multicolumn{3}{|c|}{ Bacteria } & \multicolumn{2}{|c|}{ Fungi } \\
\hline & & E.coli & $S$ aureus & B Subtilis & T. harzianum & A. brasiliensis \\
\hline \multirow[t]{4}{*}{ A.iva } & $\begin{array}{c}\text { Standard (Penicillin \& } \\
\text { Mycostatin) }\end{array}$ & 7.3 & 27 & 4.3 & 9 & 20.3 \\
\hline & $0.1 \%$ & 10.6 & 11.3 & 12.3 & 2 & 1.6 \\
\hline & $0.5 \%$ & 11.6 & 15.3 & 14.6 & 7.3 & 4 \\
\hline & $1.0 \%$ & 13.3 & 18.3 & 18.3 & 9.3 & 5 \\
\hline \multirow[t]{4}{*}{ P.scoparium } & $\begin{array}{c}\text { Standard (Penicillin \& } \\
\text { Mycostatin) }\end{array}$ & 5.3 & 6.3 & 12.3 & 8.3 & 21.6 \\
\hline & $0.1 \%$ & 12 & 11.3 & 14.3 & 4 & 4.6 \\
\hline & $0.5 \%$ & 17 & 19.3 & 17.6 & 5.6 & 7.3 \\
\hline & $1.0 \%$ & 18.6 & 21 & 18.6 & 7.3 & 7.3 \\
\hline \multirow[t]{4}{*}{ R.stricta } & $\begin{array}{c}\text { Standard (Penicillin \& } \\
\text { Mycostatin) }\end{array}$ & 5.3 & 3 & 8 & 7.6 & 24.6 \\
\hline & $0.1 \%$ & 11.6 & 15.3 & 12 & 7.3 & 2.6 \\
\hline & $0.5 \%$ & 12 & 18.6 & 14.3 & 10 & 9.6 \\
\hline & $1.0 \%$ & 13.3 & 21.6 & 19.6 & 10.6 & 10.3 \\
\hline
\end{tabular}

All the results are mean of three replicates

\section{Acknowledgement}

The authors are highly thankful to Higher College of Technology, Ministry of manpower, Alkhuwair, Muscat, Sultanate of Oman for providing necessary requirements.

\section{Conflict of interest}

Authors would hereby like to declare that there is no conflict of interests that could possibly arise.

\section{References}

Adhikari BS, Babu MM, Saklani PL, Rawat GS (2010) Medicinal Plants Diversity and their Conservation Status in Wildlife Institute of Indi (WII) Campus, Dehradun. Ethnobotanical Leaflets 14: 46-56. Available at: http://opensiuc.lib.siu.edu/ebl/vol2010/iss1/6 access on 17th January, 2016.

Ahmad Y, Fatima K, Le Quesne PPW, Atta-ur-Rahman (1983) Further alkaloidal constituents of the leaves of Rhazya stricta. Phytochemistry 22: 10171019.http://dx.doi.org/10.1590/S1415-47572013005000009

Ali BH, Tanira MO, Bashir AK, Al-Qarawi AA (2000) Effect of Rhazya stricta Dence on Monoamine Oxidase and Cholinesterase Activity and Brain Biogenic Amine Levels in Rats. Journal of Pharmacy and Pharmacology 52: 1297-1300. http://dx.doi.org/10.1211/0022357001777289
Anila L, Vijayalakshmi NR, Tian C (2002) Beneficial effect of flavonoids from Sesamum indicum, Emblica officinalis and Momordica charantia. Phytotherapy Research 14:592-595.

Bako SP, Bakfur MJ, John I, Bala EI (2005) Ethno-medicinal and phytochemical profile of some savanna plant species in Nigeria. International journal of Botany 1: 147-150.

Brain KR, Turner TD (1975) The practical evaluation of phytopharmaceuticals. 2nd Edn. Bristol: Wright Science technica Pp. 81-82.

Chhabra SC, Uiso FC, Mshiu EN (1984) Phytochemical screening of Tanzanian medicinal plants. Journal of Ethnopharmacology 11: 157-179. doi:10.1016/03788741(84)90037-0.

Emad El-deen HM (2005) Population ecology of Rhazya stricta Decne. in Western Saudi Arabia. International Journal of Agriculture and Biology 7: 932-938.

Jung M, Park M, Lee HC, Kang YH, Kang ES, Kim SK (2006) Antidiabetic Agents from Medicinal Plants. Current Medicinal $\begin{array}{lll}\text { Chemistry } & 13: 1203-1218 .\end{array}$ $10.2174 / 092986706776360860$.

Kavanagh F (1972) Analytical microbiology Part II, New York, Academic Press, Pp .126.

Miura T, Itoh C, Iwamoto N, Kato M, Kawai M, Park SR, Suzuki I (2001) Hypoglycemic activity of the fruit of the Momordica charantia in Type 2 diabetic mice. Journal of Nutritional Science and Vitaminology (Tokyo) 47: 340-344. 
Murakami A, Ohigashi H, Tanaka S, Hirota M, Irie R, Takeda N, Tatematsu A, Koshimizu K (1993) Bitter cyanoglucosides from Lophira alata. Phytochemistry 32: 1461 - 1466. DOI:10.1016/0031-9422(93)85160-S

Okine LKN, Nyarko AK, Osei-Kwabena N, Oppong IV, Barnes F, Ofosuhene M (2005) The antidiabetic activity of the herbal preparation ADD-199 in mice: A comparative study with two oral hypoglycaemic drugs. Journal of $\begin{array}{llll}\text { Ethnopharmacology } & 97 & \text { : } & 31-38 \text {. }\end{array}$ DOI:10.1016/j.jep.2004.09.048.

Pearce DW, Puroshothaman S (1992) Protecting Biological Diversity: The Economic Value of Pharmaceutical Plants. CSERGE Global Environmental Change Working Paper 9227, Centre for Social and Economic Research on the Global Environment, University College.

Posey DA (1999) Cultural and Spiritual Values of Biodiversity A Complementary Contribution to the Global Biodiversity Assessment, UNEP.

Principe PP (1991) Valuing the Biodiversity of Medicinal Plants. In: Akerele O, Heywood V, Synge H (Eds.) The Conservation of Medicinal Plants. Proceedings of an International Consultation held on 21-27th March, 1988 at Chiang Mai, Thailand, Cambridge University Press, Pp. 79124.

Reddy HS., Chakravarthi M, Chandrashekara KN, Naidu CV (2012) Phytochemical Screening and Antibacterial Studies on
Leaf and Root Extracts of Asclepias curassavica (L). IOSR Journal of Pharmacy and Biological Sciences 2:39-44.

Reddy S, Al-NeeriI , Al-Issaei H, Al-Jabri S (2015) Effect of Selective Medicinal Plant Extract on Blood Glucose, Sperm Shape and Various Physiological Parameters. American Journal of Plant Sciences 6: 1109-1115. DOI: 10.4236/ajps.2015.68115.

Rücker G, Kehrbaum S, Sakulas H, Lawong B, Goeltenboth F (1992) Acetylenic glucosides from Microglossa pyrifolia. Planta Medica 58: 266-269. DOI: 10.1055/s-2006-961450.

Sanni SS (2007) Pharmacological and Toxicological effects of Ocimum basilicum LINN. extracts in rats. PhD Thesis, submitted to the Department Veterinary Physiology and Pharmacology, Usman Danfodiyo, University Sokoto, Nigeria.

Schippmann U, Leaman DJ, Cunningham AB (2002) Impact of cultivation and gathering of medicinal plants on biodiversity: Global trends and issues. In: Biodiversity and the Ecosystem Approach in Agriculture, Forestry and Fisheries. Food and Agriculture Organization (FAO), Rome.

Wadood A, Ghufran M, Jamal SB, Naeem M, Khan A, Ghaffar R, Asnad (2013) Phytochemical Analysis of Medicinal Plants Occurring in Local Area of Mardan. Biochemistry and Analytical Biochemistry 2:144. doi: 10.4172/21611009.1000144. 